\title{
SHOP GREEN: A CASE STUDY OF TARIQ ROAD AXIS IN KARACHI
}

\author{
Yasira Naeem Pasha*
}

\begin{abstract}
The emerging concern for urban environment is currently one of the most essential ingredients of urban design theory. A commercial activity within the extents of the modern city dwells in one such environment.
\end{abstract}

The post-industrialization era has served severe limitations on the natural development of commercial activities, retailing being one of them. Today, the rather unusual transformation of retail activity has been largely endorsed on accounts of ease and comfort. However, this change has surfaced various shortcomings in terms of sustainability.

This study aims to explore an existing retail activity in the context of Karachi. The main objective of the study is to find ways to upgrade the environment of the area in which this retail activity exists. The study aims to achieve this without subscribing to the insensitive and inorganic design solutions prevalent in contemporary times. The study also aims to develop a prototype which can serve other commercial spaces within the precincts of the city and beyond. Providing convenience of use to various stakeholders involved remains at the core of the study.

The study derives a theoretical foundation through a focused literature review. Examples from other contexts are also referred. The study essentially comprises both qualitative and quantitative data which are carefully extracted from personal observations, structured questionnaires and visual documentation.

Key Words: Environmental upgradation, Commercial space, Retail activity, Pedestrian circulation, Traffic congestion.

\section{INTRODUCTION}

Environments can be perceived as envelopes enclosing various physical and virtual activities around the world. Acting as containers, these environments need to be appropriately defined with respect to the activities they support. There are several methods by which this can be achieved. Upgradation of an already-defined environment is one of these methods.

Since the $19^{\text {th }}$ century industrial revolution, continuous expansion and evolution of technological environments have dominated proceedings leading into contemporary times. In the process, physical and socio-cultural environments have significantly suffered, resulting in inadequate commercial settings across all urban hemispheres. In order to set right or improve this situation, the issue of environmental degradation needs to be promptly and competently addressed.

"Environmental degradation relates to the deterioration of the environment, both in terms of quantity and quality. It has many forms and can occur naturally or through human processes." This basic understanding of environmental degradation forms the basis for arriving at the concept of environmental upgradation.

Built environments commonly found in the constantly expanding cities of the developing world present a mingling of commercial and residential spaces. Each of these distinctive spaces carries a tendency to degrade the other. Furthermore, non-availability of facilities such as common underground infrastructure, fewer parking spaces, and lack of greenery are just some of the factors which account for the degradation of physical and socio-cultural environments in these cities. In an effort to stand shoulder to shoulder with the so-called exemplary cities, such as Dubai, the use of non-indigenous materials and unsustainable methods of development have been widely accepted. Consequently, advantages of sustainable development have been almost entirely overlooked.

Sustainable development is development that meets the needs of the present without compromising the ability of

\footnotetext{
* Architect Yasira Naeem Pasha, Assistant Professor, Department of Architecture and Planning, Dawood College of Engineering \& Technology, Karachi.
} 
future generations to meet their own need. This mode of human development has been largely disregarded in the development of commercial spaces such as Tariq Road, located in the heart of the Pakistan port city of Karachi. Although the term "sustainability" has been widely identified as the core ingredient of contemporary urban design, its transition from theory to practice is yet to be fully realized. Concerns over environmental degradation of commercial spaces are on a rise. Contradictory to satisfying such concerns purely through mechanical means, various non-mechanical strategies can be employed for reaching more pragmatic and sustainable results. Environmental qualities of a given commercial space, such as Tariq Road, can be effectively enhanced along these lines.

\section{SOME THEORETICAL INFERENCES}

The theory of imageability by Lynch (1960) can be used as a constructive tool for the upgradation of a given environment. According to this theory, imageability is the quality of a space or object which creates strong mental imagery. This makes the space more prominent, powerfully structured and user-friendly.

Shopping areas act as integral units of our environment. Consistent with the needs of time, these functional units should not only be structured but also upgraded in accordance with potential environmental concerns, changing pace of movement and scale of new construction.

This concept of conscious design is proposed keeping in view the context of Tariq Road. Accordingly, the process of
Context Sensitive Design (CSD) is taken into perspective. Context Sensitive Design is defined as a theoretical and practical approach to design that takes into consideration the needs of the users, the neighboring communities, and the environment. It involves careful planning, consideration of varying perspectives, and tailoring designs to particular project circumstances. CSD also uses a collaborative, interdisciplinary approach that includes early involvement of key stakeholders to ensure that public transportation projects are not only moving safely and efficiently, but are also in harmony with the natural, social, economic, and cultural environment.

CSD requires an early and continuous commitment to public involvement, flexibility in exploring new solutions, and an openness to new ideas. Community members play an important role in identifying local and regional problems and solutions that may better meet and balance the needs of all stakeholders. Early public involvement can help reduce expensive and time-consuming rework later on and thus contribute to sustainable urban development. Such an approach can redefine inhospitable commercial settings as places to linger, relax and cherish.

Both the above mentioned theories are taken into consideration in an attempt to redefine the environment of Tariq Road. Environment here is perceived as a shell encompassing all ingredients of what constitutes a sustainable development [Figure-1].

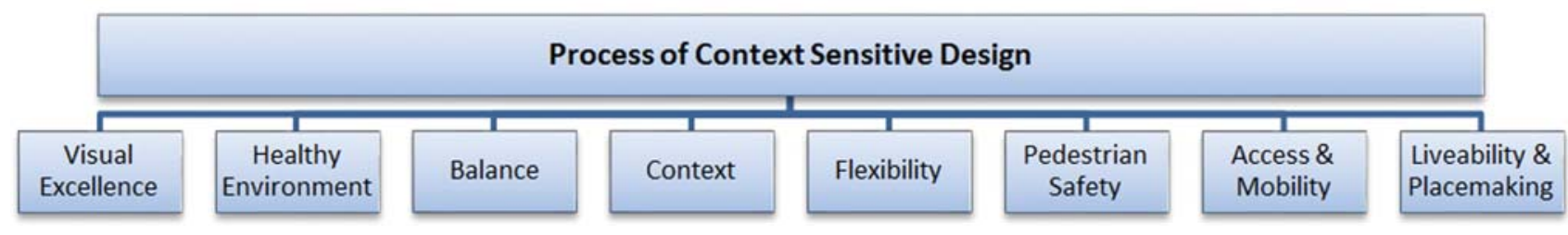

Figure-1: Process of context sensitive design - An illustration Source: Author 


\section{KARACHI: A BRIEF}

The area that now consists of Karachi was originally composed of a group of small villages including Kolachijo-Goth and the fort of Manora. It was in 1729 that Kolachijo-Goth was transformed from a fishing village into a trading post when it was selected as a port for trade with Muscat and Bahrain. By early $20^{\text {th }}$ century, Karachi transformed into a city with railroads, churches, paved streets, courts and many commercial centers as well as a magnificent harbor built by the British.

In 1947, Karachi was made the capital of the new nation of Pakistan. Its growth accelerated as a result of its new status. Being the capital, Karachi became a focal point for the new nation and this added to its status as a cultural centre in this part of the world. Although the capital later moved to Islamabad, Karachi remained the economic centre of Pakistan, accounting for a large portion of the GNP of the nation. With the passage of time, the city has evolved with respect to a high rate of urbanization. Many new locations have been added to the city in the form of both planned and unplanned additions.

\section{SIGNIFICANCE OF THE STUDY}

In general, the study signifies the use of commercial spaces in accordance with environmentally acceptable standards. It introduces ways to bring about a change in existing shopping trends by redefining the environment of Tariq Road.

The phenomenon of commercial space is studied within the unique context of Karachi and more specifically, within the context of Tariq Road. Various social relationships and problems within this area are identified and understood. Issues pertaining to the quality of commercial space, its use, the users and their needs are investigated and addressed. With the passage of time and implementation of such a proposal, the model can be employed for the improvement of other commercial spaces in the city and beyond.

\section{INFERENCES FROM CASE STUDIES}

The core idea behind the selection of precedent studies is to identify problems common to commercial activities. Although various studies have been conducted on Tariq Road, the problems identified with the help of these case studies are indeed unique in nature.

The two case studies taken into consideration are the MG
Road in Banglore, India, and the Istiklal Avenue in Istanbul, Turkey. The findings of the case studies can be summed up as follows:

- The social, environmental, and other relevant characteristics of the two commercial spaces can be compared to those of Tariq Road in terms of changes in geographical patterns. Hence, it can be concluded that the general needs of the user in each context is more or less the same.

- The pattern of retail activity in both instances is the same, which is to walk and shop. Although vehicles can be used to reach specific destinations, the primary mode of transportation remains pedestrian.

- Both commercial spaces are also treated as interactive spaces. The act of window shopping remains common to both. Similarly, Tariq Road can also be developed into a social hub adding to the economy of the city.

- In both instances, it is observed that users can easily adapt to pedestrian-bound movement in place of vehicular-bound movement, provided that the environment is inviting and comfortable.

- The solutions proposed for the upgradation of both the environments are similar in nature [Figure-2].

\section{OBJECTIVES OF THE STUDY}

- To upgrade the environment of the specified commercial space in order to make it user-friendly and sustainable.

- To develop a shopping environment without subscribing to the insensitive and inorganic design solutions prevalent in contemporary times.

- To develop a prototype which can serve other commercial spaces within the precincts of the city and beyond.

\section{RESEARCH METHODOLOGY}

The research methodology adopted involves an in-depth analysis of the selected case studies. The following tools were employed to collect the relevant data:

- Extensive surveys of the specified area

- Questionnaires for various stakeholders involved. 


\begin{tabular}{|c|c|c|c|c|c|}
\hline $\begin{array}{c}\text { S. } \\
\text { NO. }\end{array}$ & AREA & LOCATION & $\begin{array}{c}\text { PROBLEM } \\
\text { IDENTIFICATION }\end{array}$ & $\begin{array}{c}\text { PROBLEM } \\
\text { IDENTIFICATION }\end{array}$ & $\begin{array}{c}\text { PROBLEM } \\
\text { IDENTIFICATION }\end{array}$ \\
\hline 1. & $\begin{array}{l}\text { MG Road } \\
\text { Pune } \\
\text { Banglore }\end{array}$ & India & $\begin{array}{l}\text { - } \quad \text { Traffic congestion } \\
\text { - } \quad \text { High thermal conditions } \\
\text { - } \text { High pollution } \\
\text { - Change in the landuse } \\
\text { into malls } \\
\text { - No interactive spaces to } \\
\text { enjoy }\end{array}$ & Pedestrianization & 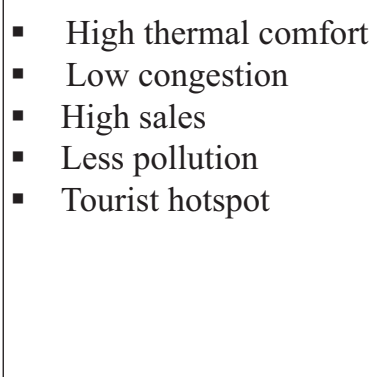 \\
\hline 2. & $\begin{array}{c}\text { Istiklal } \\
\text { Street } \\
\text { Instanbul }\end{array}$ & Turkey & 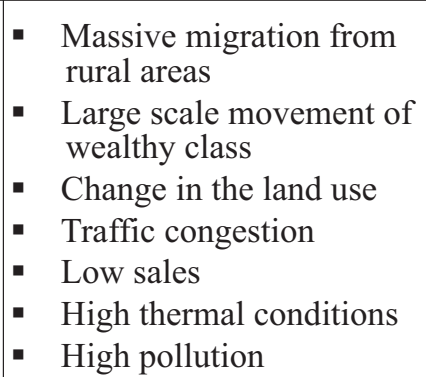 & Pedestrianization & $\begin{array}{l}\text { - } \quad \text { High thermal comfort } \\
\text { - } \quad \text { Less pollution } \\
\text { - } \quad \text { Tourist hotspot }\end{array}$ \\
\hline 3. & $\begin{array}{l}\text { Tariq } \\
\text { Road } \\
\text { Karachi }\end{array}$ & Pakistan & $\begin{array}{l}\text { - } \text { Change in land use } \\
\text { - } \quad \text { Traffic congestion } \\
\text { - } \text { Low sales } \\
\text { - } \text { High thermal conditions } \\
\text { into malls } \\
\text { - No interactie spaces to } \\
\text { enjoy }\end{array}$ & $\begin{array}{l}\text { 1. } \begin{array}{l}\text { Conventional solution: } \\
\text { Pedestrianization with } \\
\text { change in traffic plan. }\end{array} \\
\text { 2. Radical Solution: } \\
\text { Underpass for public } \\
\text { transport along with } \\
\text { pedestrian ground level } \\
\text { with change in traffic } \\
\text { plan }\end{array}$ & $\begin{array}{ll}\text { - } & \text { High thermal comfort } \\
\text { - } & \text { Low congestion } \\
\text { - } & \text { Tourist hotspot } \\
& \end{array}$ \\
\hline
\end{tabular}

Figure-2: Comparative analysis.

- $\quad$ Review of visual documentation.

- Review of available literature.

Initially, research questions provide the way forward. This is followed by the collection of data. Observations and questionnaires account for primary data. Secondary data is gathered from documentation including government publications and past research.

Results are evaluated following the collection of data from questionnaires. This is later arranged in the form of bar graphs for comparative analysis. The results are further analyzed to provide recommendations for the final set of solutions and proposals.
A frame of analysis is also developed based on the following set of considerations:

- Analysis of qualitative data

- Conversion of quantitative data into tabulated format

- Development of cause and effect relationship

- $\quad$ Research findings

- Proposal 


\section{TARIQ ROAD}

Tariq Road has a considerable impact on the urban environment and social life of Karachi. It is extremely popular amongst the masses and accounts for one of the busiest commercial spaces in the city.

The section of Tariq Road selected for environmental upgaradation can be divided into two zones:

- Starting from the Liberty Signal, turning to the SouthEast towards Jheel Park, and including Jheel Park itself.

- Going straight from the Liberty Signal down towards the roundabout at the intersection with Sharah-eQuaideen (Allah wali chorangi).

The surroundings of the commercial space can be defined by:

- Kashmir Road to the North-West

- Jheel Park to the South-East

- Shaheed-e-Millat Road to the North-East

- Sharah-e-Quaideen to the South-West

\section{SITE CHARACTERISTICS}

\subsection{Location}

Tariq Road is a 100 feet wide street with shops on both sides. Apart from its basic morphological composition, it is a cluster of streets forming an intricate network. Acting as one of the major strategic roads of the city, it is connected to the Bahadurabad Roundabout in the North-East, where the commercial activity starts.

\subsection{Accessibility}

The site is accessible from all sides. A mesh of secondary streets can be found along each side of its length. This accessibility is further reinforced by all kinds of public transport available at and adjacent to the area.

\subsection{Vehicular Traffic Flow}

The vehicular traffic flow accounts for the major activity during the day transforming the street from a commercial activity zone to a major circulation artery. Space for expansion of the street is no longer available.

\subsection{Link with City Nodes}

The commercial space is connected to major areas such as PECHS and SBahadurabad, Saddar, the popular business district and city center, is located nearby. Some of the city's major hospitals are also located in the vicinity [Figure-3].

\section{OBSERVATIONS BASED ON QUALITATIVE DATA}

\subsection{Shopping Malls' Atmosphere}

The atmosphere within the shopping malls located in the area is rather inviting. These malls offer comfortable shopping environments, spaces for entertainment, and well-designed dining areas. They provide a fair account of the needs of the user - of what is considered acceptable and what is not.

\subsection{Availability of Vacant Land}

Vacant plots of land in the area can support various functions which can further enhance the environmental quality of the commercial space.

\subsection{New Construction}

New construction in the area fails to address the requirements of the commercial space. This insensitive approach to design needs to be reversed in order to establish a more coherent image of the area.

\subsection{Building Facades}

Glass facades in the area appear to be gaining popularity amongst various retailers. This recent development needs to be carefully addressed with respect to questions pertaining to high energy consumption[Figure-4].

\subsection{Haphazard Vehicular Traffic Flow}

The vehicular traffic in the area is composed of both private and public means of transportation. Unavailability of parking spaces contributes to unusual patterns of traffic movement [Figure-5]. 


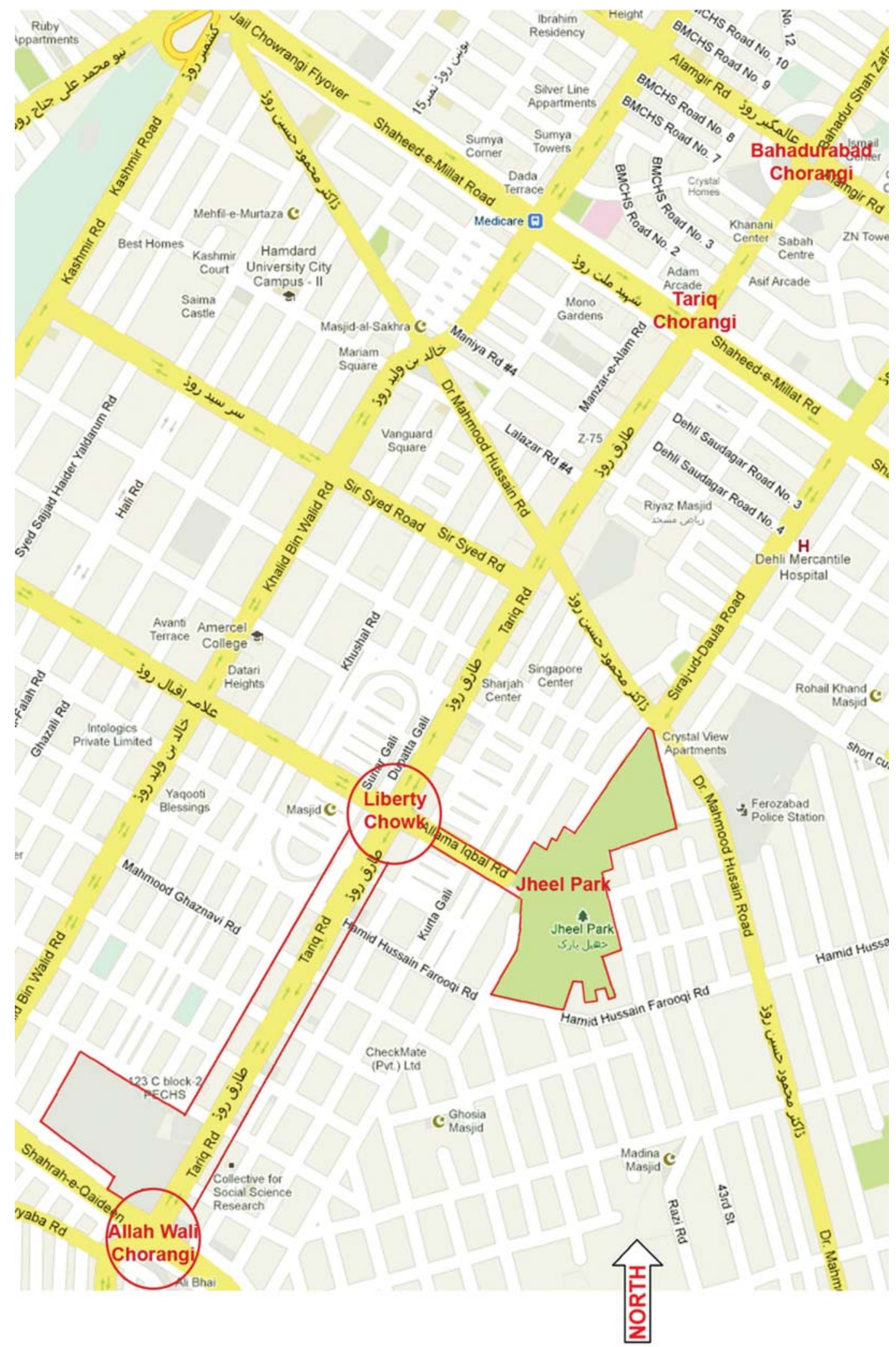

Figure-3: Map showing link with major city nodes. 


\subsection{Prolonged Traffic Jams}

Unusual patterns of traffic movement result in prolonged traffic jams in the area. This condition is further aggravated by numerous temporary and permanent impediments along the streets.

\subsection{Lack of Pedestrian Movement}

Dominated by vehicular traffic, the character of the area is by no means conducive to pedestrian circulation. Infringed walkways ensure that pedestrian movement is reduced to a minimum. The importance of visiting customers as prime stakeholders is clearly underestimated.

\subsection{Use and Misuse of Plots}

Although the vacant plots in the area are authorized for commercial use, they are subjected to partial or complete misuse. They can be strategically transformed into parking spaces in pursuit of improving both vehicular and pedestrian circulation.

\subsection{Mixed Use of Plots}

Despite the commercial nature of the area, buildings are constructed to serve both commercial and residential purposes.

\subsection{Lack of Landscape Elements}

The area exhibits an absence of planned landscape elements. Dominated by man-made structures and congested vehicular traffic flow, the area remains deprived of both hard and soft landscape. This condition significantly dampens the aesthetic

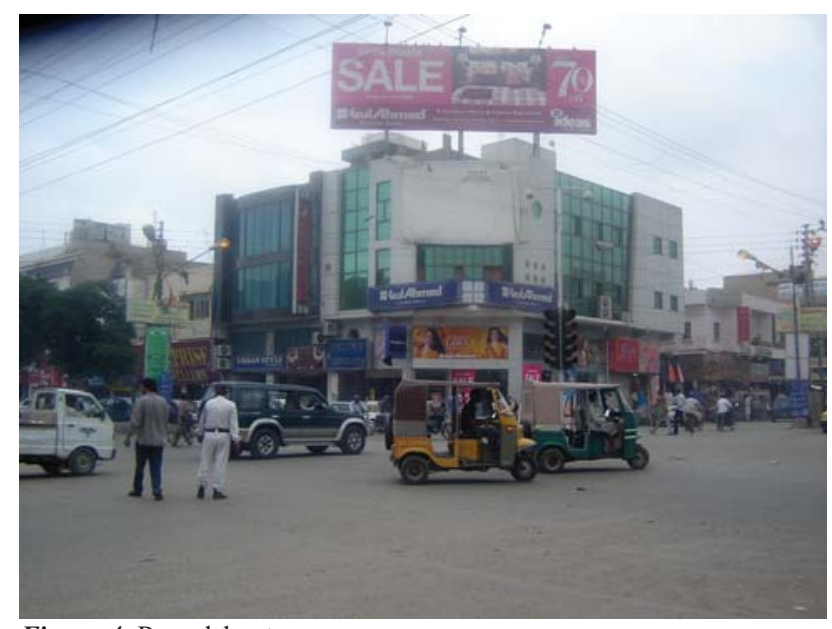

Figure-4: Roundabout. qualities of the area.

\section{TRAFFIC COUNT}

The statistics related to traffic characteristics indicate that the intensity of vehicular traffic increases gradually at the stroke of mid-day. These statistics also indicate that the vehicular traffic flow in the area is predominantly composed of personal vehicles. Other modes of transport including buses, wagons, rickshaws, etc. also access the area throughout the day.

The high percentage of personal vehicles accessing the area for shopping purposes contributes to road-side parking which, in turn, contributes to frequent and prolonged traffic congestions.

The statistics also show that in the peak traffic hours of the day, pedestrian counts are not negligible. These pedestrian counts also increase with the increase in vehicular traffic at the mid-day. It is also observed that vehicle/pedestrian ration stands approximately to 1 . The current pattern of movement in the area dictates more space for vehicles and very less for pedestrian, whereas a major portion of it is occupied by hawkers. This contrast needs to be addressed by different means [Figure-6].

\section{IDENTIFICATION OF PROBLEMS}

One of the major problems identified in the area is the absence of planned parking spaces. Frequent and prolonged traffic jams caused by haphazard parking patterns on either side of the street are a common sight during peak hours. Mass numbers of vehicles carelessly parked along the street also contribute to the increase in temperatures during the

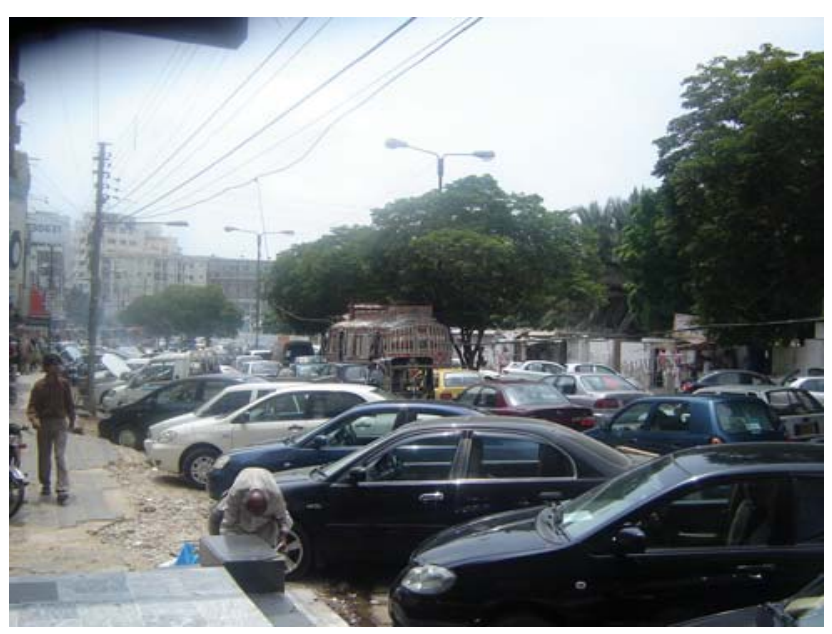

Figure-5: Parking at Tariq road. 


\begin{tabular}{|c|c|c|c|c|c|c|c|c|}
\hline \multicolumn{2}{|c|}{ TOTAL 16 HR TRAFFIC } & \multicolumn{6}{|c|}{ PEAK HOUR TRAFFIC } & \multirow[t]{3}{*}{$\begin{array}{l}\text { VEH/PCU } \\
\text { RATIO }\end{array}$} \\
\hline \multirow[t]{2}{*}{ Veh. } & \multirow[t]{2}{*}{ PCUs } & \multicolumn{3}{|c|}{ Morning(1100-1200) } & \multicolumn{3}{|c|}{ Mid-day $(1200-1300)$} & \\
\hline & & Veh. & PCU & $\%$ & Veh. & PCU & $\%$ & \\
\hline 98,592 & 93,082 & 7,378 & 6,507 & 7.48 & 8,204 & 7,503 & 8.32 & 1.059 \\
\hline \multicolumn{9}{|c|}{ TRAFFIC COMPOSITION } \\
\hline & & & & & \multicolumn{4}{|c|}{ COMPOSITION } \\
\hline \multicolumn{5}{|c|}{ MODES } & \multicolumn{2}{|c|}{ TOTAL } & & PERCENTAGE \\
\hline \multicolumn{2}{|c|}{ 1. Motor Cycles } & & & & \multicolumn{2}{|c|}{21,668} & & 21,98 \\
\hline \multicolumn{3}{|c|}{ 2. Cars / Jeeps / Suzuki } & & & \multicolumn{2}{|c|}{55,188} & & 55.98 \\
\hline \multicolumn{3}{|c|}{ 3. Rickshaws } & & & \multicolumn{2}{|r|}{7,127} & & 7.23 \\
\hline \multicolumn{3}{|c|}{ 4. Ford Wagons } & & & \multicolumn{2}{|r|}{3,270} & & 3.32 \\
\hline \multicolumn{3}{|c|}{ 5. Mini Buses } & & & \multicolumn{2}{|r|}{5,628} & & 5.71 \\
\hline \multicolumn{3}{|c|}{ 6. Buses $/$ Trucks } & & & \multicolumn{2}{|r|}{4,707} & & 4.77 \\
\hline \multicolumn{3}{|c|}{ 7. Trailers } & & & \multicolumn{2}{|r|}{188} & & 0.19 \\
\hline \multicolumn{3}{|c|}{ 8. Pedal Cycles } & & & \multicolumn{2}{|r|}{729} & & 0.74 \\
\hline \multicolumn{3}{|c|}{ 9. Animal / Men Carts } & & & & 87 & & 0.09 \\
\hline
\end{tabular}

Figure-6: Traffic count at Tariq road.

Source: Traffic Engineering Bureau. KDA, Karachi. A survey report January - February 1993.

day. It has been observed that visitors are generally reluctant to walk along the street in such pitiable conditions. In contrast, they are willing to walk long hours in well-resourced environments such as those found in shopping malls. Therefore, it can be safely concluded that lack of proper parking facilities combined with traffic congestions, poor air-quality, noise pollution, infringed walkways, etc. have simultaneously contributed to the environmental deterioration of Tariq Road.

According to a survey report prepared by the Traffic Engineering Bureau, Karachi, about $60 \%$ of people visiting Tariq Road use personal vehicles. Another study related to the commercialization of roads in Karachi reveals the adverse impacts of the resulting increase in traffic volumes across the city. Survey of the roads closely linked to Tariq road revealed that a large number of respondents $(83 \%)$ were of the view that the traffic volumes have increased to a great extent as a result of increasing commercial activities in these areas. The figures were fairly consistent for all other roads in the vicinity, with the highest percentage recorded along Khalid Bin Walid Road (90\%). The study also revealed that over $90 \%$ of the respondents considered poor air quality and increase in noise pollution to be the most damaging consequences of increasing traffic volumes in these areas.

In order to analyze the patterns of traffic movement and their impacts, the area was divided into 14 segments. Each of these was sequentially analyzed and conclusions were drawn. Here it must be emphasized that the roundabouts in the area were studied separately owing to their strategic physical locations. For instance, the Liberty Roundabout is one of the most prominent landmarks in the area since it is positioned at the intersection between Allama Iqbal Road and Tariq Road. It also serves as a connecting node when heading towards the Jheel Park [Figure-7 \& 8].

\section{WALKABILITY INDEX KARACHI}

In July 2009, the Urban Resource Center along with students from Indus Valley School of Art and Architecture, Karachi, and the National College of Arts, Lahore, voluntarily carried out a survey in an attempt to determine the Walkability Index in Karachi. The survey was conducted using the 


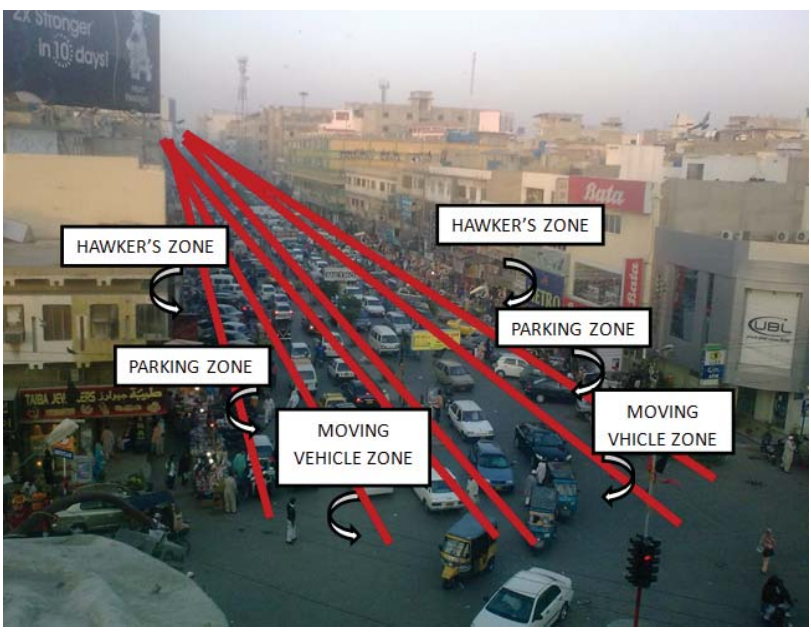

Figure-7: View of the area from Liberty roundabout.

Global Walkability Index (GWI), a standardized field survey tool developed by the World Bank. This index was designed to evaluate the quality of pedestrian environment in a city. The objective of the survey was: (a) to popularize the concept of walkability as an important aspect of sustainable urban development, and (b) to mobilize all stakeholders to work with the concerned authorities in order to improve the pedestrian infrastructure of the city.

The survey was carried out in four commercial/residential areas of the city, namely Clifton, Tariq Road, Gurumandar and NIPA. Each of these areas measure 250,000 square meters and cover 36 main roads with a combined length of 20.58 kilometers. The survey was conducted during early evenings when traffic congestion and crowding on public transport is at its highest. The main findings of the survey were:

- The Walkability Index of Karachi (50) measured much lower than that of Bangkok (121).

- The Walkability Index of Tariq Road proved to be much higher than those of the other three areas. This was mainly because Tariq Road attracts the highest number of pedestrians and comprises a relatively better quality of pedestrian infrastructure. However, the score remained much lower than that of Bangkok.

Poor quality of sidewalks, crosswalks, and lack of accessibility for the physically impaired proved to be the major factors which contributed to the low score.

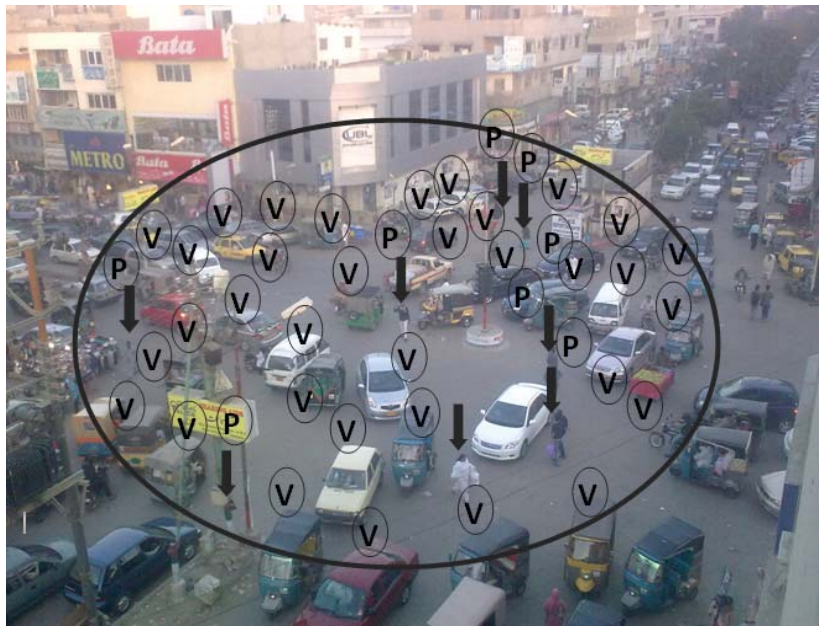

Figure-8: View of Liberty roundabout.

The picture reveals three clearly distinctive zones. No space for pedestrian movement can be identified.

The picture reveals massive traffic congestion at Liberty Roundabout. Irregular patterns of vehicular and pedestrian circulation can be seen.

\section{IMPORTANT FINDINGS OF THE SURVEY}

This section only provides the selected information derived from the field survey.

\subsection{Problems on Tariq Road}

$64 \%$ of the users identified the absence of planned parking facilities as the major problem in the area. $44 \%$ highlighted traffic congestion whereas $34 \%$ pointed towards inadequate pedestrian facilities. $38 \%$ considered lack of greenery to be a major setback to the environment. Mass presence of hawkers, lack of appropriate eating spaces, and lack of law and order were classified as some of the other problems in the area [Figure-9].

\subsection{Choice of Movement}

$72 \%$ of the users acknowledged the enhancement of pedestrian movement as the major tool in the upgradation of the environment. $12 \%$ called for the improvement of vehicular circulation whereas $16 \%$ called for the enhancement of both forms of public circulation [Figure-10]. 


\subsection{Suggestions pertaining to the enhancement of shopping environment}

$58 \%$ of the users suggested the addition of a parking plaza to enhance the shopping environment. $46 \%$ of the users suggested a pollution-free environment; $44 \%$ suggested the elimination of illegal encroachments; $40 \%$ suggested the improvement of aesthetics; $22 \%$ suggested the maintenance of law and order; and $2 \%$ recommended better layouts for the shops [Figure-11].

\section{REFERENCES FROM STRATEGIC PLAN KARACHI 2020}

The environment of a given commercial space can be greatly enhanced by the curtailment of vehicular traffic movement together with the facilitation of pedestrian movement. This can also lead to the possibility of adding more commercial activities in the area. Initially, only the study area can be stripped of vehicular traffic. Later, the process can be replicated on a much wider scale.

Defining measures must be taken to improve the transit facilities in the area. These may include:

- Reforming parking strategies

- Enhancing sidewalks and crosswalks

- Introducing pedestrian malls

- Establishing zones for hawkers

- Removing illegal encroachments

- Defining bus routes

- Introducing shuttle services

- $\quad$ Exploring mass transit options

- Introducing parking terminals along the periphery

- Improving intersections

- Installing and relocating traffic signals

- Re-arranging traffic movement pattern

- Improving linkages to radial and ring roads

- Restricting animal-driven carts

\section{THE PROPOSAL}

As concluded previously, the environment of Tariq Road is defined by irregular patterns of vehicular traffic movement. Recurrent traffic congestion has considerably degraded the environment of the area making it unfavorable for shopping and leisure.
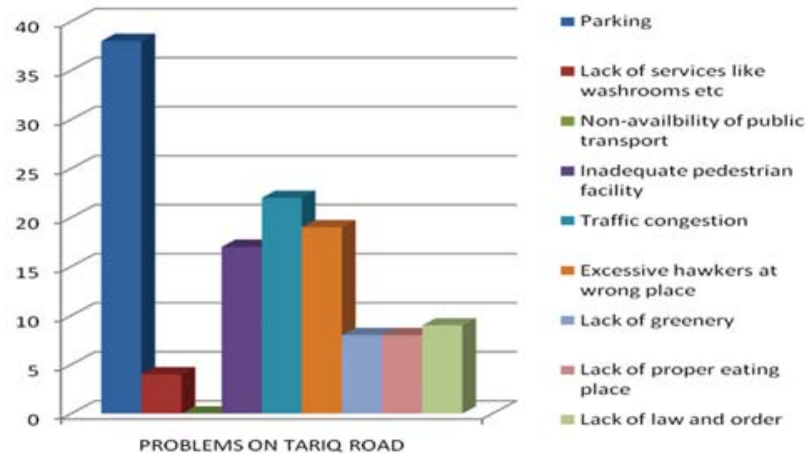

Figure-9: Problems at Tariq road.

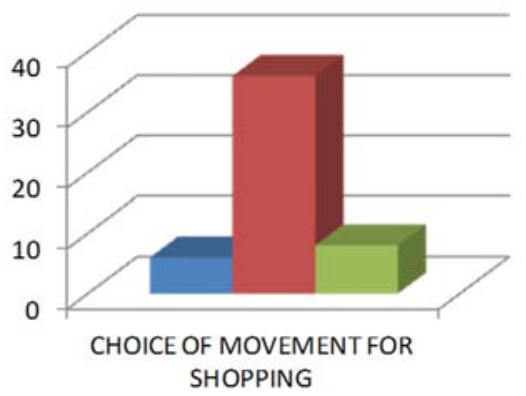

Vehicular Path

- Pedestrian

= Both side by side

Figure-10: Choices of movement.

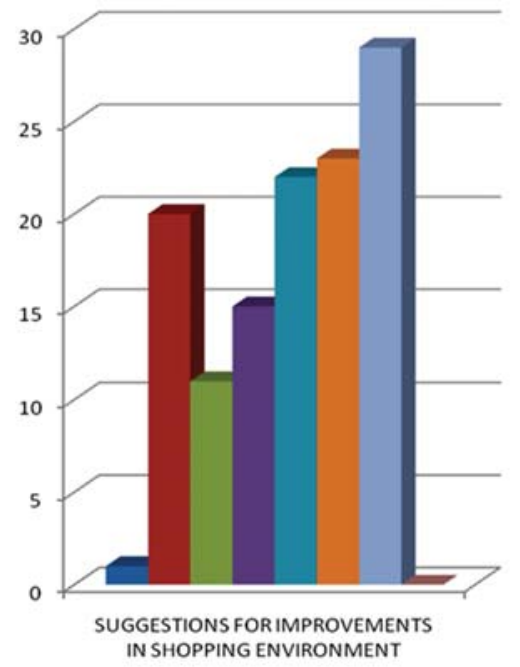

- Better Design layout of shops

- Improvement in aesthetics of the area

= Maintainance of law and order

- Provision of services

- Stoppage of

encrochments and hawkers

= Pollution free environment

- Parking plaza

= Anyother

Figure-11: Suggestions for improvement. 


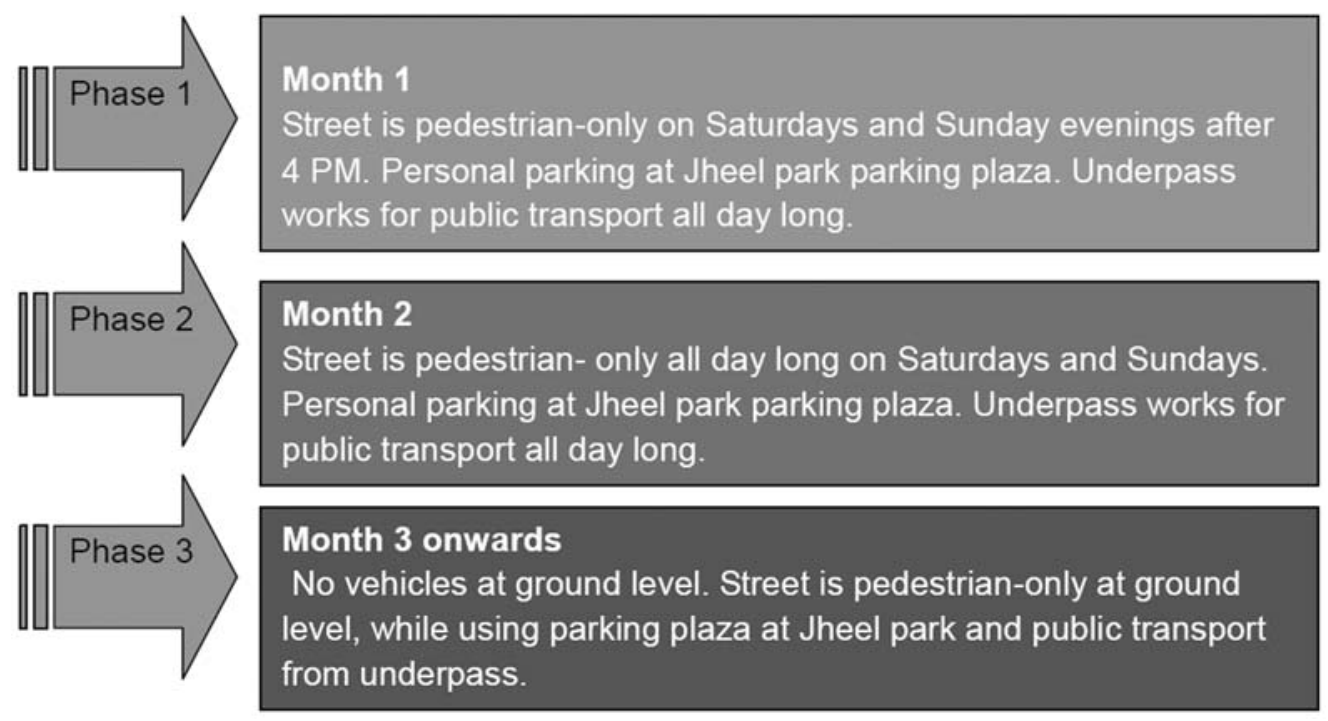

Figure-12: Three-phase process.

The proposal for the environmental upgradation of Tariq Road is largely derived from the theories of Imageability and Context Sensitive Design. The two case studies referred have also played an important role. The proposal can be summed up by the following set of measures:

- Providing a pedestrian thoroughfare in the selected area

- $\quad$ Providing a parking plaza within the premises of Jheel Park

- Providing space for hawkers in the currently misused vacant plots of land

- Providing a new traffic plan for vehicles approaching the area

- Providing an emission-free shuttle service which is to be maintained by the retailers [Figure-12]

\subsection{Benefits}

- Unobstructed views of the various shops along the street can facilitate both the retailers and the customers

- Reduction in air and noise pollution
- Organized arrangement of spaces for parking, hawkers and shopping

- Comfort and security for all stakeholders involved

\subsection{Implementation Plan for Pedestrianization}

Sudden changes to urban environments may not be widely acceptable to the stakeholders as opposed to gradual changes. Therefore, the pedestrianization of Tariq Road is proposed as a three-phase process.

\subsection{Proposed Traffic Plan}

The new traffic plan can be divided into two distinct approaches, both of which can be overlapped in order to fully serve the environmental upgradation tactics.

\subsubsection{Conventional Approach}

In this approach, the vehicular traffic flow heading towards Tariq Road will be redirected. This will result in a car-free Tariq Road which can then be transformed into a pedestrian street.

The new traffic plan for the area will include:

- $\quad$ Traffic from Shaheed-e-Millat will be directed towards 
the proposed parking plaza at Jheel Park via Siraj-udDaula Road.

- $\quad$ Traffic from Sharah-e-Quaideen will be directed towards the proposed parking plaza at Jheel Park via Dr.
Mehmood Hussain Road.

- Tariq Road will be closed for vehicular traffic at Sharahe-Quaideen and Shaheed-e-Milat Road [Figure-13].

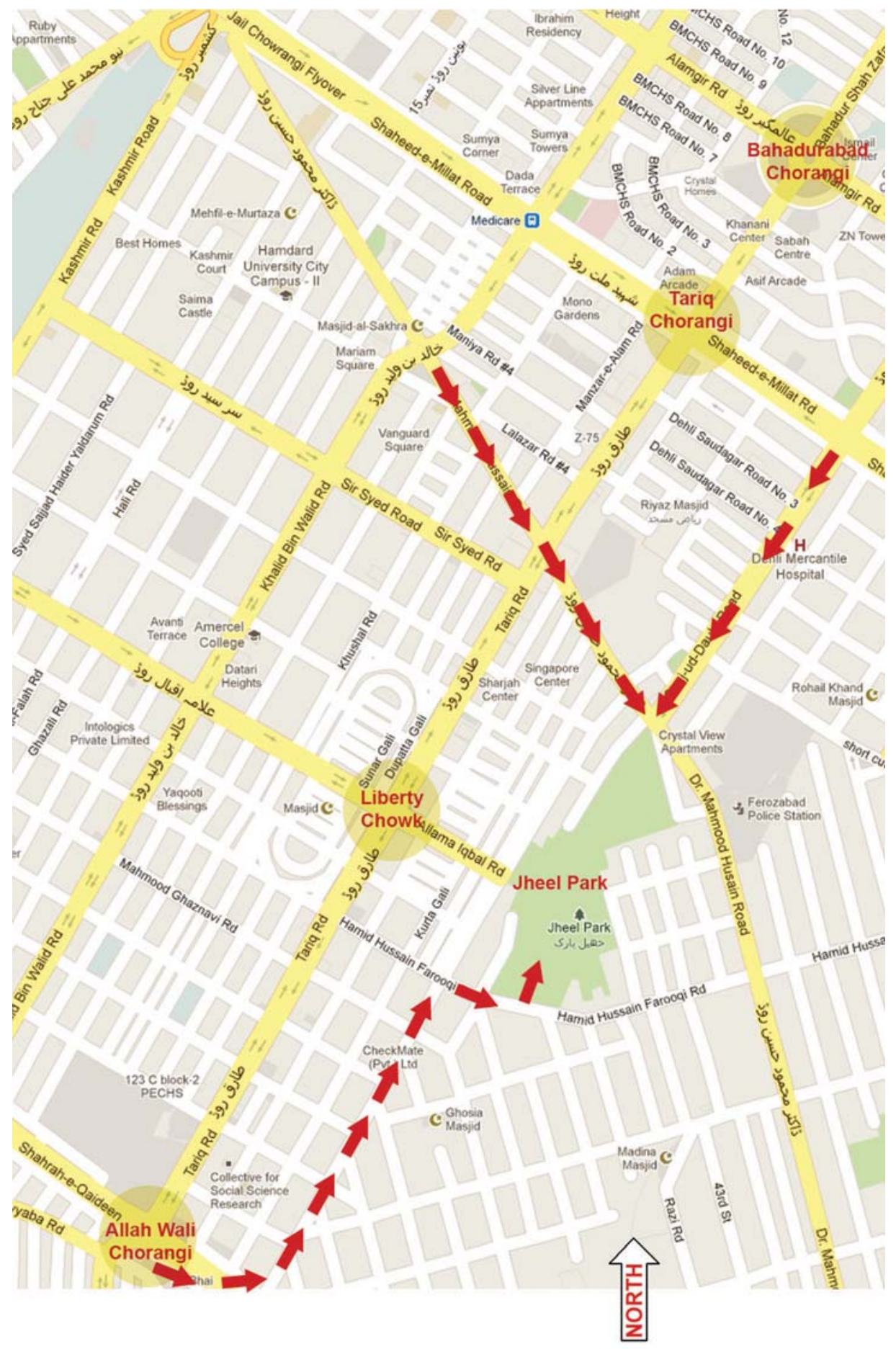

Figure-13: New traffic plan - Conventional approach. 


\subsubsection{Radical Approach}

This approach considers the construction of an underpass along the existing length of Tariq Road. While the underpass will be used for vehicular circulation, the upper or ground level will be used for pedestrian circulation. It is well understood that the translation of current vehicular pattern on to another level can lead to similar traffic problems.

Therefore, the following is proposed:
- The underpass will serve the public transport system alone and facilitate one-way traffic flow only.

- Three major junctions, namely Bahadurabad Roundabout, Liberty Roundabout and Allah Wali Roundabout, will serve to connect the two levels [Figure-14].

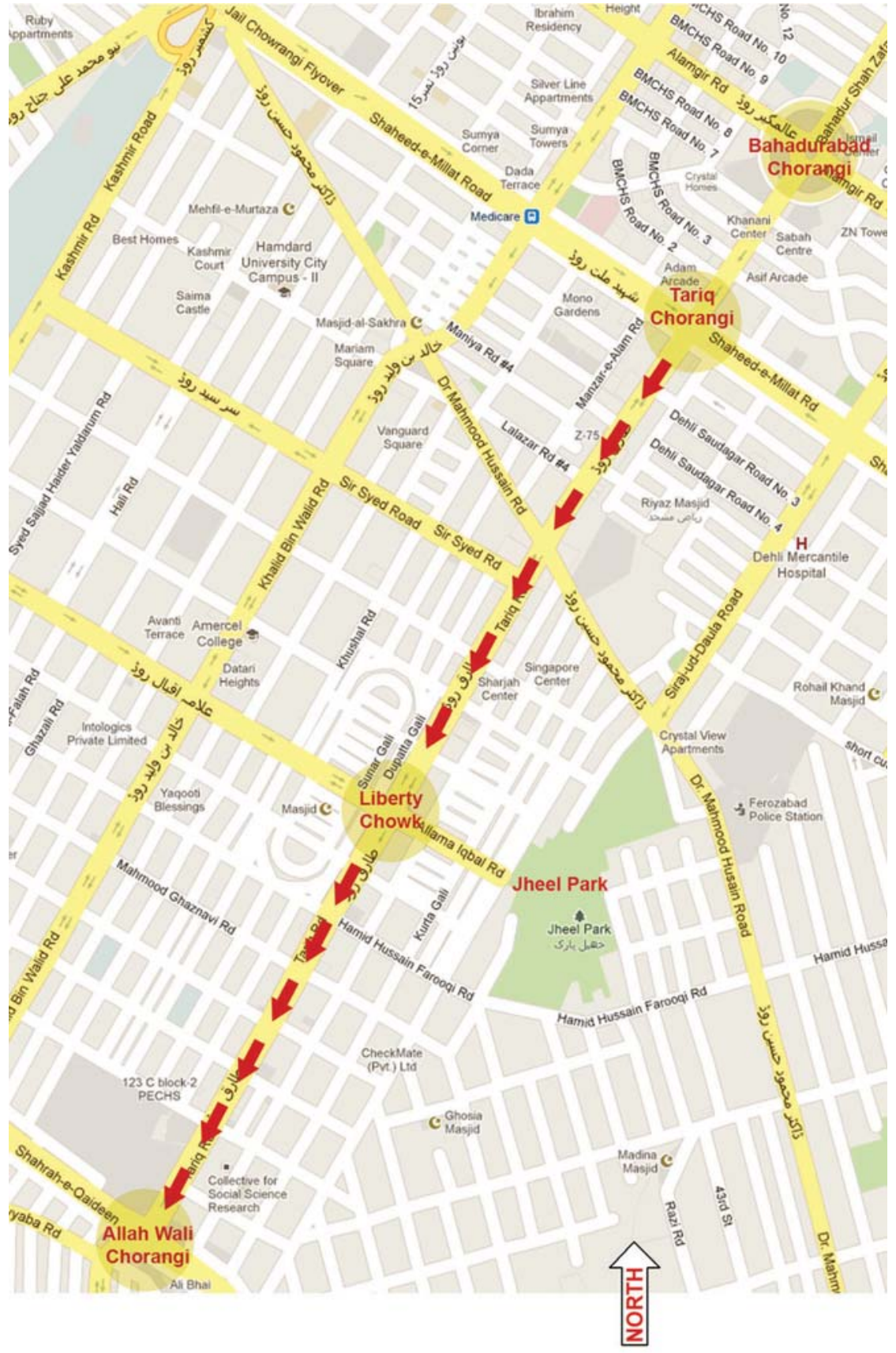

Figure-14: New traffic plan - Radical approach. 


\subsection{Proposal for Hawkers Zone}

Vacant plots in the area are proposed for the relocation of hawkers. Such a proposal has been previously welcomed in other commercial spaces of the city such as Meena Bazaar. The City District Government will be responsible for instructing and managing the hawkers in these newly defined zones.

\subsection{Proposal for Parking Plaza}

Proposal for structured parking facility is not new to Tariq Road. It has been previously incorporated in the commercialization plans outlined for the area. The facility was planned within the premises of Jheel Park. However, plans to convert the entire park into a massive parking area are abandoned. Instead, a parking plaza is proposed to be constructed within a relatively small portion of the park. This will ensure that the integrity of the park is maintained for maximum public use [Figure-15, $16 \& 17$ ].

It can be safely said that by re-organizing traffic and creating appropriate room for pedestrian spaces and providing desirable number of parking stalls, reasonable upgradation in the shopping environment can be achieved.

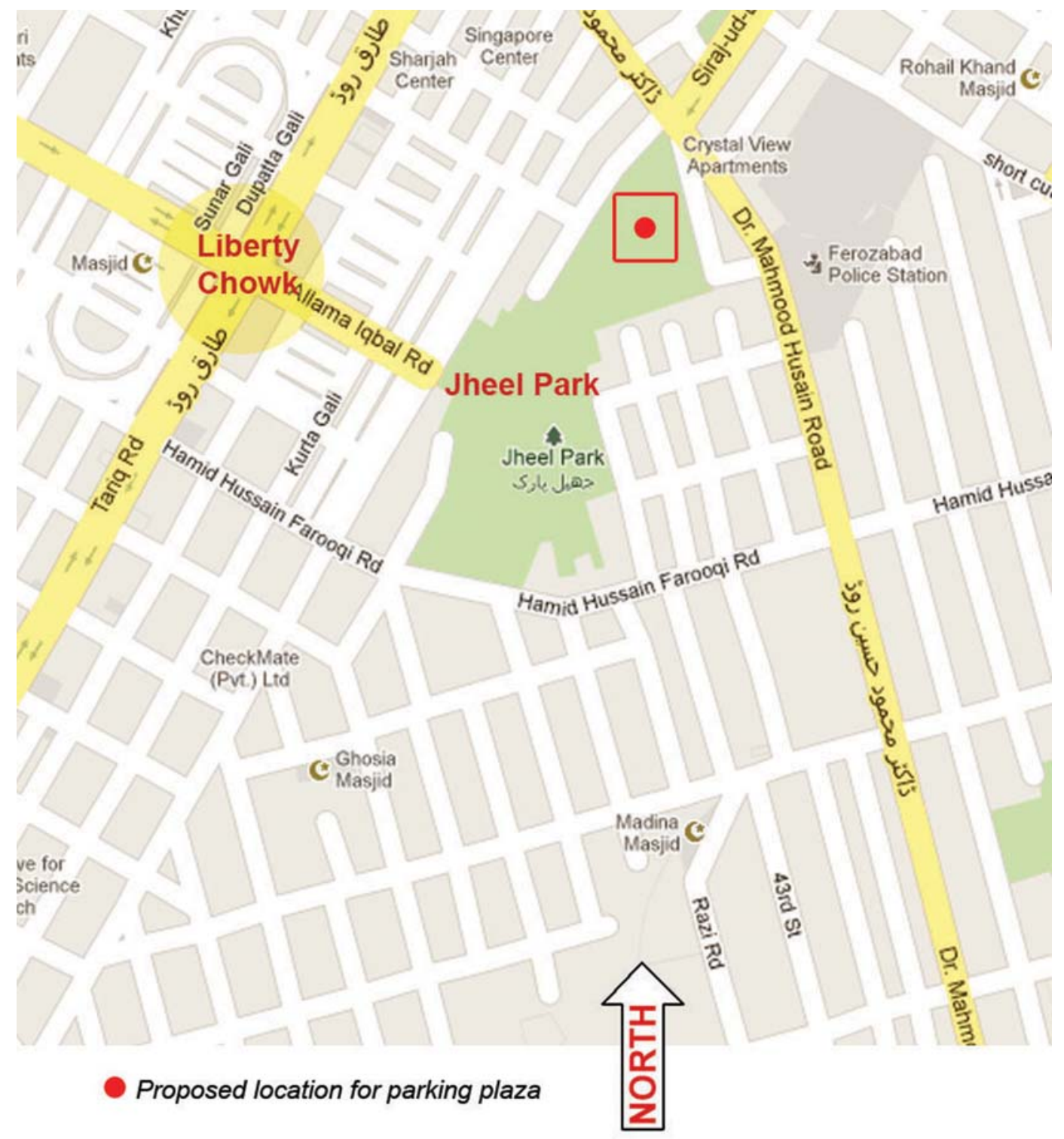

Figure-15: Area proposed for the construction of parking plaza. 


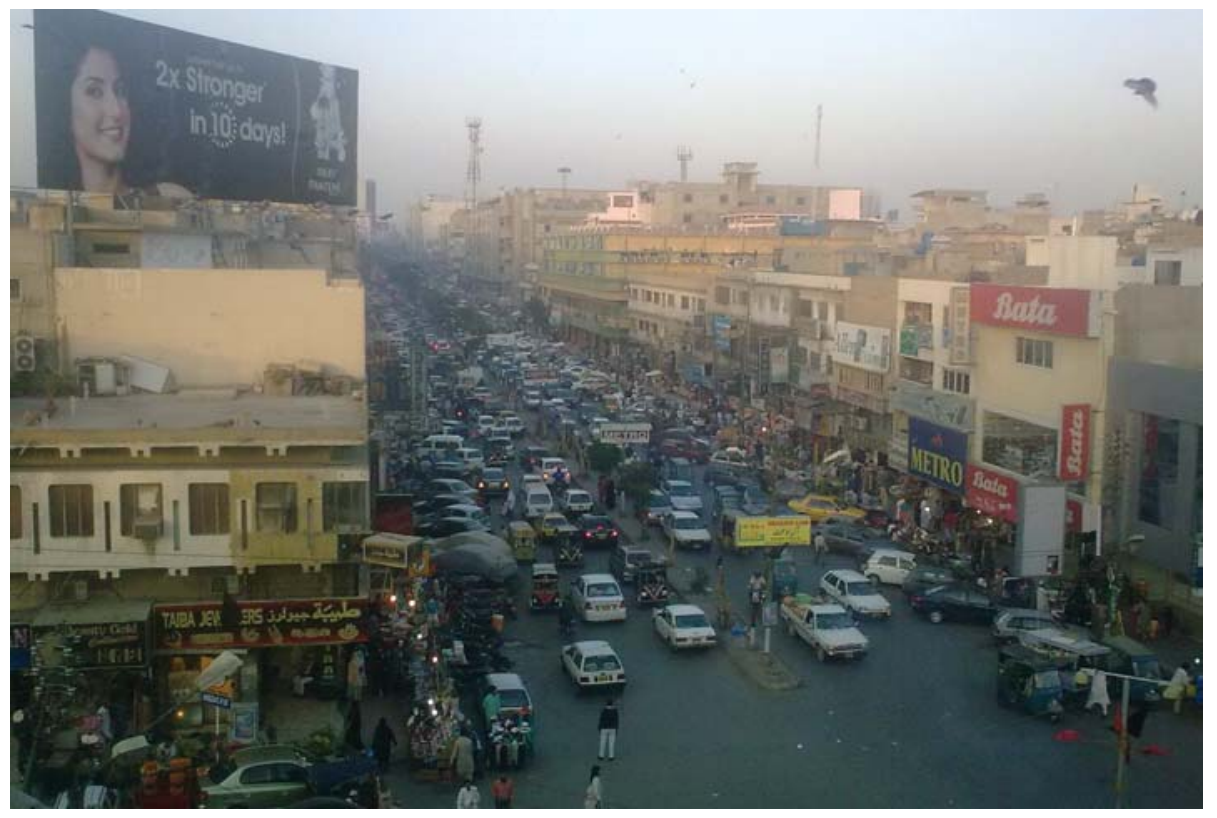

Figure-16: Existing view of Tariq road.

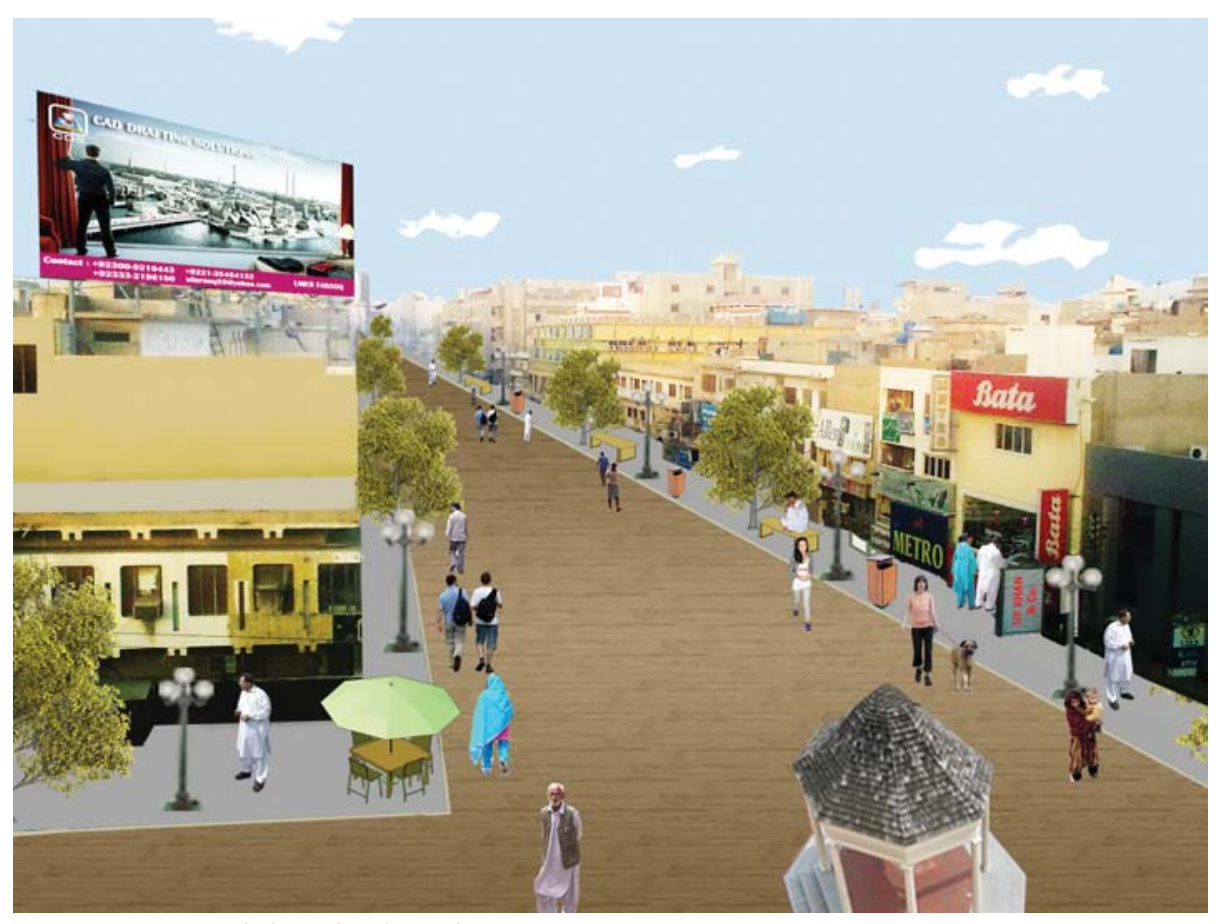

Figure-17: Proposed view of Tariq road. 


\section{Acknowledgement:}

The author is indebted to the significant input of Mr Sami Chohan, Faculty Member at the Department of Architecture and Planning at NED University for improving earlier version of this paper.

\section{REFERENCES}

(1987). Report of the World Commission on Environment and Development: Our Common Future; Development and International Co-operation: Environment; Our Common Future. Chapter 2: Towards Sustainable Development; p.8

Jorge E. Hardoy, Diana Mitlin and David Satterwaite. (1992) “Environmental Problems in Third World Ciies”, EarthScan Publications Ltd, London.

Baillie, A. F. (1980) “Kurrachee: Past, Present and Future”, Thacker Spink \& Co., Calcutta.

Comprehensive Environmental Design Report. (1993) Reference Section, Department of Architecture and Planning library, DCET, Karachi.

(2007). A survey report. Traffic Engineering Bureau, CDGK, Karachi.

Hasan Arif. (2002), Understanding Karachi, Planning and Reform for the Future, City Press, Karachi.

Hasan Arif. (2002). The Unplanned revolution, Observations on the Process of Socio Economic Change in Pakistan, City Press, Karachi.

Anwar Farhan. (2008). Commercialization of Traffic corridors in Karachi: The citizens speak. p.10

Kumar Ranjit. (2005). Research Methodology-A Step by Step Guide for Beginners, (2 ${ }^{\text {nd }}$ edition), Singapore, Pearson Education.

Tolley RS and Turton BJ. (2000). Transport Systems, Policy and Planning: A Geographical Approach pp. 182-183

Lynch, Kevin (1960); The Image of the city, Cambridge MA.

A survey report January- February. (1993).Traffic Engineering Bureau. KDA, Karachi.

Thomson Micheal. (1977). Great cities and their traffic.

Wilhelm Kirch. (2008).Encyclopedia of Public Health: Volume 1: A - H,

(2010). Transport Engineering Bureau, City District government, Karachi.

(2010). Census Department, Karachi Development Authority, Karachi.

(2010). Department of Transportation, University of Minnesota, Minneapolis. 